\title{
ESTUDO DO PROCESSO PRODUTIVO EM UMA INDÚSTRIA DO RAMO MOVELEIRO
}

\author{
Jaqueline Franciele Klauck ${ }^{1}$, Bruna Steffler ${ }^{2}$, \\ Alexandre Chapoval Neto $^{3}$
}

RESUMO: 0 trabalho desenvolvido na área de Administração, contempla o estudo do processo produtivo em uma indústria do ramo moveleiro. Tem-se conhecimento que as empresas buscam diversas formas eficazes de gerenciar e controlar a qualidade dos produtos oferecidos, obtendo resultados satisfatórios, evitar desperdícios e ser referência no mercado de atuação. Dessa forma, é possível verificar a relevância de um processo de produção alinhado e com um bom desempenho. Diante do exposto, definiu-se como problema da pesquisa: como o estudo do processo produtivo pode contribuir para a organização de uma indústria de móveis sob medida? O levantamento realizado objetivou-se propor ações de melhorias no processo produtivo da indústria moveleira. Em relação aos métodos de abordagem foram utilizados os métodos dedutivo, qualitativo e quantitativo. Quanto aos métodos de procedimentos utilizou-se o descritivo e estudo de caso. As técnicas utilizadas para a coleta de dados foram: observação, pesquisa documental, levantamento fotográfico, entrevista. As técnicas de análise de dados foram a planilha eletrônica e análise de conteúdo. Os resultados do estudo evidenciaram oportunidades de melhoria no processo produtivo. Utilizou-se a ferramenta $5 \mathrm{w} 1 \mathrm{~h}$ para elaboração do plano de ação onde foram apresentadas algumas ações que irão contribuir para o processo produtivo da indústria, como a organização do ambiente, alocação da matéria prima, iluminação, refugos, ampliação da estrutura física e a criação de um álbum de produções já realizadas. A partir da execução do plano de ação de cada melhoria, as mesmas garantirão maior credibilidade, organização e rendimento nas tarefas executas.

Palavras-chave:Processo produtivo. Qualidade. Indústria.

Submissão: 07/06/2020

Aceite: 06/07/2020

DOI:10.47591/RAC.2674-9203.2020v2n2.art1-1-15

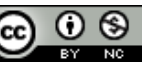

Este trabalho está licenciado com uma Licença Creative Commons Atribuição-NãoComercial 4.0 Internacional.

\footnotetext{
${ }^{1}$ E-mail: jaquefklauck@gmail.com

2 E-mail: brunasteffler8@gmail.com

${ }^{3}$ Mestre em Engenharia de Produção pela Universidade Federal de Santa Maria (UFSM). Coordenador de Núcleos de Pesquisa da Sociedade Educacional Três de Maio (SETREM). E-mail: alexandrechapoval@setrem.com.br
} 
O desenvolvimento da indústria moveleira brasileira deu-se a partir dos meados dos anos 90, principalmente pela abertura comercial promovida pelo governo. Nesse período é possível perceber o investimento da indústria em equipamentos de qualidade e a valorização interna do mercado moveleiro, introduzindo, assim, novos consumidores, que antes não participavam do mercado, de acordo com os dados da Associação Brasileira das Indústrias do Mobiliário (2016).

A elaboração de um estudo do processo produtivo, traz informações relevantes para as organizações contribuindo com o alcance dos objetivos. Além do mais, ainda é possível observar detalhadamente cada processo, identificando oportunidades de melhorias e desperdícios referentes ao tempo e a matéria-prima, destacam Slack, Brandon-Jones e Johnston (2018).

Os benefícios com o estudo do processo produtivo são diversos para a organização, principalmente na qualidade do serviço executado, a contenção de problemas, a reavaliação das etapas do processo e a busca continua da qualidade e melhorias. Destaca-se que são imprescindíveis para um processo eficaz, conforme Slack, Brandon-Jones e Johnston (2018).

Atualmente, o setor moveleiro no estado do Rio Grande do Sul possui mais de 2,5 mil empresas, o que gera próximo a 41 mil postos de trabalho, a sua produção chega a 79,3 milhões de peças, no valor estimado de $\mathrm{R} \$ 11,5$ bilhões. Esses dados são provenientes da MOVERGS (Associação das Indústrias do Estado do Rio Grande do Sul). Dessa maneira, o estudo apresentou como objetivo a identificação de ações de melhorias no processo produtivo, por meio de um mapeamento do processo produtivo, para dessa maneira ser possível analisar e propor ações de melhorias. Sendo identificado o seguinte problema: como o estudo do processo produtivo pode contribuir para a organização de uma indústria de móveis sob medida?

0 desenvolvimento do artigo justifica-se pela finalidade e necessidade do conhecimento de uma linha de produção de uma indústria moveleira, identificando, dessa maneira, oportunidades de melhorias no sistema produtivo, principalmente, referente a eventuais desperdícios, estrutura e layout da organização, contribuindo para a melhoria contínua da qualidade dos produtos ofertados e garantindo, assim, a satisfação dos seus clientes.

Em primeiro momento apresenta-se o referencial teórico com a apresentação de conceitos referentes a administração da produção, mapeamento do processo produtivo, qualidade e layout. Em segundo momento contemplamos a metodologia utilizada no estudo e, em seguida, a apresentação dos resultados identificados, com a apresentação da organização, a identificação de oportunidades de melhorias e a priorização das atividades a serem executadas em um momento futuro.

\section{REVISÃO DE LITERATURA}

Neste momento serão apresentados conteúdos produzidos por autores como Corrêa, Machado, Slack e Pradella, referente aos assuntos de Administração 
da produção, qualidade, mapeamento do processo e layout, embasando cientificamente o estudo.

\subsection{ADMINISTRAÇÃO DA PRODUÇÃO}

Conforme Slack, Chambers e Johnston (2009) a administração da produção retrata a forma pela qual as empresas produzem bens e serviços, e busca trabalhar assuntos práticos referente a problemas reais. A administração da produção é utilizada para o desenvolvimento das atividades, decisões e responsabilidades dos gestores da produção.

De acordo com Corrêa et al. (2008), administração da produção possui como objetivo oferecer suporte para a organização, visando atingir os objetivos estratégicos, planejando os pontos que terão que ser trabalhados no futuro, programar as atividades da produção e garantir ao cliente prazos que atendam suas necessidades.

\subsection{MAPEAMENTO DO PROCESSO}

Scucuglia (2007) define mapeamento de processo como uma atividade que tem a finalidade de apresentar fielmente, como ocorrem as operações internas, de tal modo a informar quais seus pontos fortes, onde estão as não conformidades, e apresenta um fluxo de informações dentre diferentes processos e particularizar, quais são de fato as entregas que cada cliente interno possui o dever de realizar no objetivo de finalizar o produto.

Para Pradella, Furtado e Kipper (2012), o mapeamento de processo possui como objetivo gerenciar os processos de uma organização, bem como as metodologias de mapeamento e gestão de processos, é considerada uma forma de contribuir para os gestores terem resultados satisfatórios, além de proporcionar uma melhor visão dos processos possibilitando ao gestor identificar pontos que possam ser melhorados.

“O mapeamento de processo envolve simplesmente a descrição de processos em termos de como as atividades relacionam-se umas com as outras dentro do processo" (SLACK; CHAMBERS; JOHNSTON, 2009, p. 101).

\subsection{QUALIDADE}

Machado (2012) conceitua qualidade sendo "um valor conhecido por todos, no entanto definido de forma divers por diferentes grupos ou camadas da sociedade". O que significa que cada pessoa possui uma percepção diferente sobre um mesmo produto ou serviço, pelo fato de cada indivíduo possui necessidades e experiências distintas.

Camargo (2011) destaca que a qualidade deve ser vista além do aspecto controle, mas vastamente como ferramenta da gestão, sendo determinante influencia para cultura e hábitos, levando para processos produtivos eficiente e uma organização competitiva no mercado de atuação.

"O controle da qualidade é voltado para o gerenciamento estratégico da qualidade, no qual a preocupação maior é poder concorrer no mercado, buscando 
tanto satisfazer as necessidades do cliente como a do próprio mercado." (Machado, 2012, p,35)

Para os autores Slack, Chambers e Johnston (2009, p. 583), "os fluxogramas podem ser usados para obter um entendimento antes do melhoramento". 0 ato de registrar cada estágio do processo auxilia para identificar os fluxos mal organizados, sendo uma ferramenta que apresenta as oportunidades de melhoramento e esclarecer a forma de trabalhar de uma operação, tornando possível detectar áreas problemáticas, na qual não existe nenhum procedimento para lidar com um conjunto particular de circunstâncias.

Rivas Junior (2010) descreve que a ferramenta 5W2H é basicamente um formulário para execução e controle das atividades, onde é possível atribuir as responsabilidades e determinar qual a forma que o trabalho deve ser realizado, bem como o departamento, motivo e prazo de conclusão e por fim os custos envolvidos para que a ação seja concluída.

Segundo Vieira Filho (2012), o plano de ação é uma ferramenta mundial e de fácil utilização. É conhecido por $5 \mathrm{~W} 1 \mathrm{H}$ ou $5 \mathrm{~W} 2 \mathrm{H}$, as siglas significam: $5 \mathrm{~W}$ : What? (o que), Who? (Quem), When? (Quando), Why? (Por que), Where? (Onde) e $2 \mathrm{H}$ : How? (Como), e How much? (Quanto custa).

As ferramentas da qualidade são técnicas que são utilizadas no decorrer do trabalho com o intuito de analisar e propor soluções para os problemas encontrados, que interferem no bom desempenho dos processos de trabalho, o que proporciona controle e melhoria na tomada de decisão.

\subsection{LAYOUT}

Para os autores Davis, Aquilano e Chase (2001), o layout tem por finalidade adequar o fluxo de trabalho de materiais através da fábrica, e também organizar um padrão de tráfego, que facilite tanto para clientes como para trabalhadores em uma empresa.

De acordo com Cury (2006), o layout representa a disposição dos diferentes postos de trabalho nos devidos espaços da empresa, procurando sempre melhorar a adaptação das pessoas envolvidas ao ambiente de trabalho, assim como desenvolver o arranjo dos móveis, máquinas, equipamentos e, também matériasprimas.

Para Paranhos Filho (2007), um fluxo bem definido concede um rápido atravessamento do produto pelo sistema produtivo. O layout é de extrema importância para a que a produtividade ocorra de forma adequada, pois o fluxo do processo pode ser otimizado ou até mesmo prejudicado conforme a disposição dos equipamentos e espaço físico.

Layout segundo Chiavenato (2004), que também é conhecido como arranjo físico, é à disposição de máquinas e equipamentos em uma organização, que busca facilitar o andamento mais apropriado dos processos e reduzir os desperdícios no sistema, nesse sentido, o layout tem como principal finalidade preencher o ambiente interno da empresa da forma mais adequada, visando dar uma melhor aparência a organização, uma melhor adaptação aos colaboradores e clientes e um ambiente que satisfaça e facilite a realização das atividades no trabalho. 
O layout fabril tem um impacto significativo nos desempenhos e nos resultados da empresa, é importante planejar corretamente a alocação das maquinas e analisar o espaço físico. Bem como, permite eliminar as falhas no processo produtivo. Com o intuito de melhorar os resultados e o processo produtivo foi elaborado um layout como sugestão para o proprietário.

\section{MÉTODO}

Referente a metodologia utilizou-se o método dedutivo para realizar consultas na literatura vinculado com o tema, sendo que Güllich, Lovato e Evangelista (2007) destacam que o método é a modalidade de raciocínio lógico que faz uso da dedução para obter uma conclusão através de determinados objetivos. Dessa maneira, buscou-se conhecer a produtividade, a estrutura física e o mapeamento do processo produtivo da indústria de móveis, para assim ser possível identificar melhorias no processo de produção. A abordagem qualitativa, Lovato (2013) destaca uma visão mais abrangente, apresentando conclusões descritivas onde não resultam da coleta de dados numéricos e análise estatística, sendo assim de caráter exploratório, utilizou-se para descrever o mapeamento do processo produtivo, a identificação de oportunidades e, por fim, propor ações de melhorias através da ferramenta 5W1H. E a abordagem quantitativa, para Lovato (2013) é adquirida através de dados numéricos e análise, que é o planejamento, a execução, a coleta de dados e análise dos resultados, foi utilizada para identificação de melhorias no processo produtivo, sendo possível apresentar numericamente dados referente aos desperdícios que ocorrem na indústria moveleira.

No que diz respeito aos métodos de procedimentos, utilizou-se o método descritivo, sendo que Güllich, Lovato e Evangelista (2007) retratam como a observação, para assim monitorar, acompanhar, classificar, registrar e descrever a processo produtivo da empresa em estudo e, por fim, para identificar e propor melhorias nesse processo. 0 estudo de caso, segundo Gil (2002) é o estudo de um ou mais objetos, permitindo um conhecimento amplo e detalhado da organização, sobre o processo de produção, os dados foram obtidos através de visitas na indústria, entrevistas e levantamento fotográfico.

A pesquisa teve desenvolvimento a partir de um estudo de caso em uma empresa do ramo de móveis sob medida, localizada na região Noroeste do estado do Rio Grande do Sul, de porte pequeno e do ramo familiar, que atua no mercado desde o ano de 2014, oferecendo diversos serviços e produtos produzidos sob medida, conforme necessidade do cliente. A escolha da empresa deve-se a temática da pesquisa estabelecida no componente curricular, desse modo buscou-se explorar o ambiente produtivo da empresa, oferecendo dessa maneira benefícios para ambos os envolvidos.

As técnicas de coleta de dados são indispensáveis para obtenção dos resultados, dessa maneira utilizaram-se como técnicas a observação, examina fatos ou fenômenos, além dos perceptíveis, através do olhar e da escuta (GÜLLICH; LOVATO; EVANGELISTA, 2007); dessa maneira acompanhou-se o processo produtivo, ambiente e layout da empresa. A pesquisa documental, de acordo com Marconi e Lakatos (2018) limita-se a documentos, podendo ser escritos ou não, na qual foi utilizada para embasamento na ordem de fabricação do catálogo de 
produtos produzidos e bem como o sequenciamento de produção e a entrevista, que ocorreu em dois momentos, com o proprietário e responsável pelo ambiente produtivo, buscando informações sobre a história da empresa, produtos fabricados, fornecedores, conhecimento do processo produtivo, desperdícios e expectativas do proprietário.

Os dados obtidos foram analisados de forma qualitativa, referente aos dados da entrevista, utilizou-se a análise do conteúdo, para criação do fluxograma, descrição do mapeamento do processo produtivo, sugestão do layout e identificação das oportunidades de melhorias. Chizzotti (2006, p. 98) destaca a análise do conteúdo como "o objetivo da análise de conteúdo é compreender criticamente o sentido das comunicações, seu conteúdo manifesto ou latente, as significações explícitas ou ocultas". Também destaca-se a importância da utilização da planilha eletrônica, para criação do fluxograma.

\section{ANÁLISE E DISCUSSÃO DOS RESULTADOS}

Nesta sessão serão apresentadas a organização em estudo, fluxograma e oportunidades de melhorias identificadas.

\subsection{APRESENTAÇÃO DA ORGANIZAÇÃO}

A empresa em estudo trata-se de uma empresa de fabricação de móveis sob medida, localizada na região Noroeste do estado do Rio Grande do Sul, Brasil, de pequeno a médio porte sendo uma organização familiar que buscou empreender e busca mercado de atuação desde 2014.

Atuando com um sistema de produção puxado desenvolve os mais variados tipos de produtos, utilizando a matéria-prima MDF, sendo os mesmos da linha de cozinhas, salas, quartos, lavanderias, closet, escritório e dentre demais pedidos solicitados.

A fim de contribuir significativamente com o desenvolvimento da organização buscou-se conhecer seu processo e ambiente produtivo, observando-o e descrevendo o mesmo passo a passo do fluxograma, que será apresentado na Figura 1. 
Figura 1 - Fluxograma

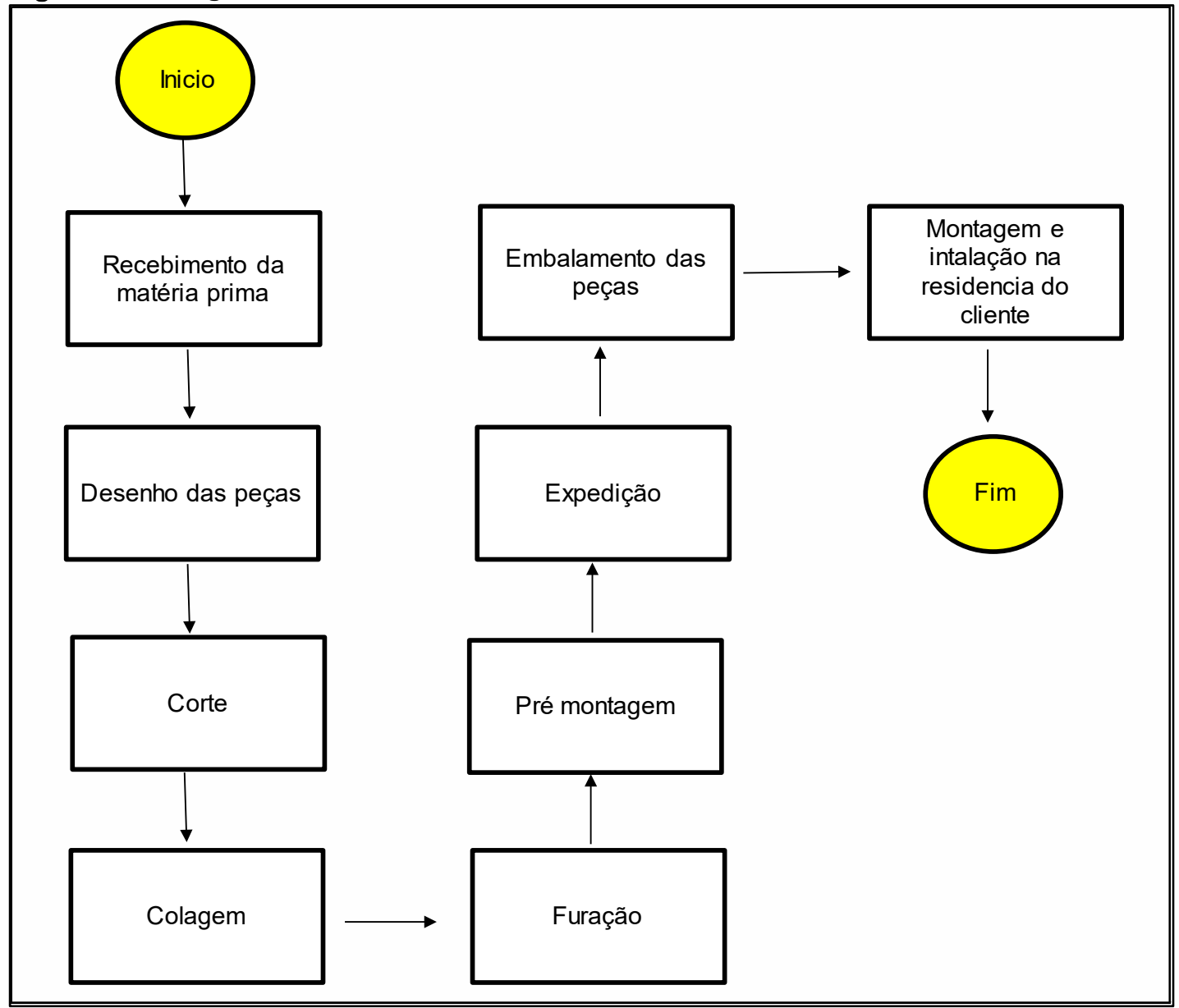

Fonte: os autores (2020).

A partir do recebimento da matéria-prima, a mesma é estocada e é realizado o desenho da peça necessária e realizado o corte. No setor de corte é o momento de definição do formato de cada componente. Posteriormente, as peças são direcionadas a área de colagem para colar as fitas na chapa, após destina-se o material a furadeira de bancada para furação dos encaixes para executar a montagem do móvel solicitado na residência do cliente.

A respeito do layout da organização, a empresa em estudo apresenta um espaço pequeno para produção, estoque, pré-montagem e escritório. Desse modo, o espaço atual é organizado da maneira apresentada na Figura 2. 0 layout foi construído com o auxílio da ferramenta Planner 5D, disponível na internet. 
Figura 2 - Layout atual

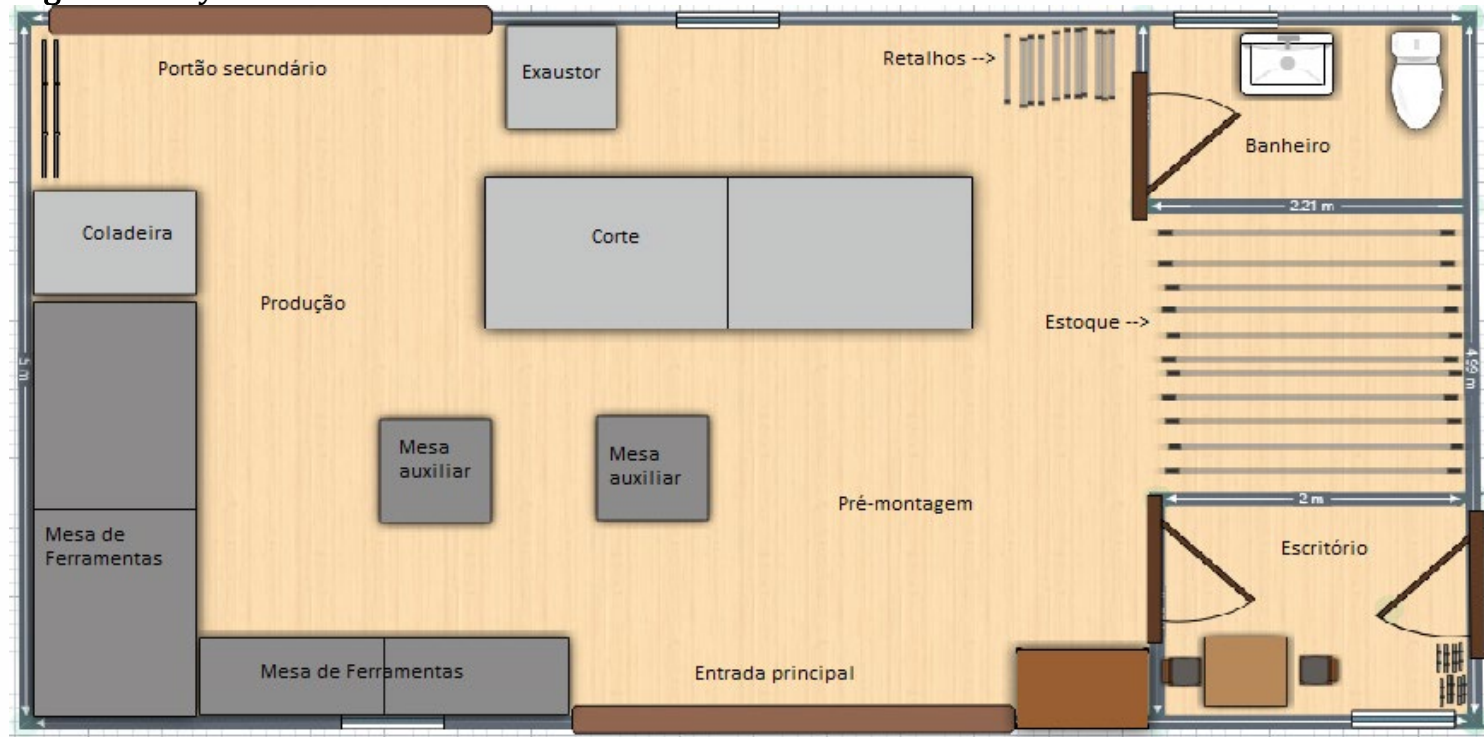

Fonte: os autores (2020).

Slack, Brandon-Jones, Johnston (2018) o layout, também conhecido como arranjo físico, significa o posicionamento dos recursos de transformação, bem como a aparência dos mesmos. O layout é importante para evitar fluxos longos e confusos, custos altos, longos processos, filas de espera, etc. Pode-se notar que a disposição do layout da organização está de acordo para o espaço disposto para produção.

Durante as visitas realizadas, pode-se perceber a necessidade de ampliação do espaço pelo próprio proprietário decorrente da grande demanda de pedidos, possibilidade de aumento de estoque e também a possibilidade de antecipação de pedidos. Desse modo, desenvolveu-se uma sugestão de layout a partir de ampliação do prédio.

Na Figura 3 está apresentado a nova proposta de layout para organização em estudo. Esse novo layout foi pensado como sugestão por diversos motivos, sendo alguns deles o espaço pequeno e a falta de um espaço adequado para atender os mais diversos tipos de clientes que a empresa possui ou que buscam o serviço da empresa.

Figura 3 - Proposta de layout

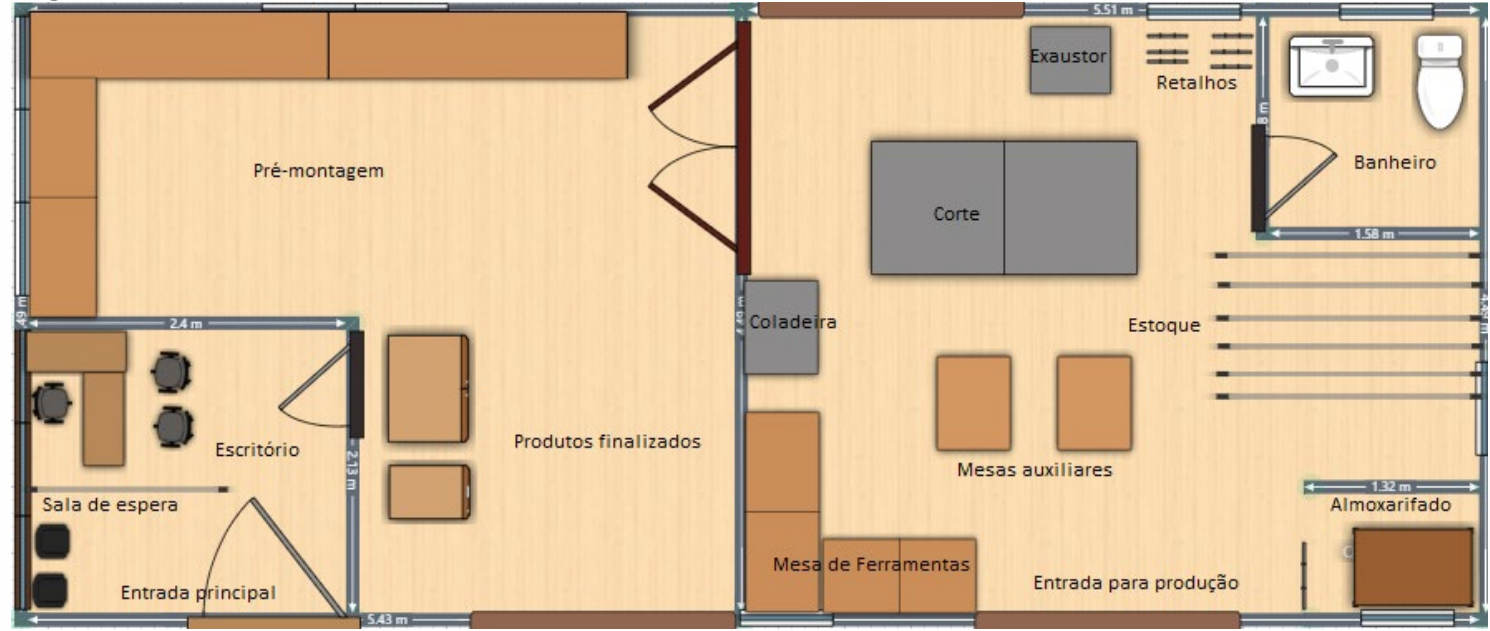

Fonte: os autores(2020). 
Slack, Brandon-Jones, Johnston (2018) destacam que a estética do layout é importante, principalmente em casos em que o cliente possui acesso ao interior das operações. 0 termo "servicescape" descreve a perspectiva e o sentimento de clientes dentro de determinado ambiente, destacando que as condições do ambiente, sinais e símbolos de operação irão criar uma "experiência ambiental". Desse modo, a realocação do escritório para a nova área a ser construída tem como objetivo principal o cliente sentir confiança e credibilidade no serviço que será ofertado, diferente do que se passa com a estrutura do layout atual, em que o cliente é atendido na grande maioria das vezes no próprio ambiente de produção, havendo poluição visual e interferência auditiva.

\subsection{IDENTIFICAÇÃO DE MELHORIAS}

Durante as visitas e observações realizadas foram elencadas um conjunto de ações de melhorias no ambiente organizacional da empresa, buscando assim melhorar o fluxo de produção e o seu ambiente. A seguir serão apresentadas algumas oportunidades de melhoria na organização em estudo.

Organização do ambiente: durante as visitas realizadas constatou-se que o ambiente produtivo encontrava-se desorganizado em sua totalidade, causando uma imagem desmotivadora para os visitantes, clientes, colaboradores e proprietário, sendo um aspecto importante que a empresa deveria levar em consideração por receber a maioria dos seus clientes em seu ambiente produtivo.

Iluminação: Slack, Brandon-Jones, Johnston (2018) destacam que a projetação do ambiente de trabalho influência principalmente no desenvolvimento de funções e na percepção do cliente. A iluminação é necessária para desempenhar a atividade satisfatoriamente em diferentes setores. Desse modo, constatou-se que o ambiente possui uma estrutura de iluminação inadequada, por apresentar uma iluminação fraca e com instalação que necessita de reparos, podendo comprometer o desenvolvimento das atividades rotineiras ou outro problema com impacto maior para a empresa.

Estoque de matéria-prima: a constatação de desorganização, pode acarretar em danos e imperfeições por conta do mau armazenamento.

Ampliação da estrutura física: evidenciou-se que a estrutura física necessita ser ampliada para demanda atual de pedidos que a organização possui, podendo melhorar assim sua apresentação física.

Novos colaboradores: a empresa atualmente trabalha com dois colaboradores fixos, dessa maneira como oportunidade de melhoria destaca-se a importância da contratação de um funcionário para o administrativo e atendimento aos clientes, para dessa maneira não perder novos negócios.

Refugos: observou-se que na organização a existência de muitos refugos de matéria-prima, desse modo evidenciou que algumas podem ser reaproveitadas, porém devem alocadas em um local correto e separadas conforme os tamanhos. Também o descarte correto dos refugos que não podem mais ser reutilizado.

Álbum de apresentação de projetos finalizados: identificou-se que a empresa não possui um álbum de projetos para apresentação aos clientes, então 
como sugestão e oportunidade seria a criação de um álbum específico de cada projeto já realizado.

Apresentadas as oportunidades de melhorias, nota-se que a empresa possui diversos pontos a melhorar e que irão contribuir significativamente com o desenvolvimento das atividades e crescimento da organização.

\subsection{PRIORIZAÇÃO DAS ATIVIDADES A SEREM DESENVOLVIDAS}

Para priorização das atividades a serem desenvolvidas, obteve-se apoio a ferramenta da Matriz GUT, para assim determinar a gravidade, a urgência e a tendência de cada oportunidade de melhoria proposta anteriormente.

Está evidenciado na Figura 4, por ordem de importância as melhorias a serem desenvolvidas e colocadas em prática pela organização.

Figura 4 - Prioridade das atividades

\begin{tabular}{|c|c|c|c|c|c|}
\hline Matriz G.U.T \\
\hline Oportunidade de melhoria & G & U & T & Pontuação & Classificação \\
\hline Organização do ambiente & 5 & 4 & 5 & 100 & $1^{\circ}$ \\
\hline Estocagem de matéria-prima & 5 & 3 & 3 & 45 & $2^{\circ}$ \\
\hline Iluminação & 4 & 4 & 2 & 32 & $3^{\circ}$ \\
\hline Refugos & 3 & 3 & 2 & 18 & $4^{\circ}$ \\
\hline Álbum de apresentação de projetos finalizados & 2 & 2 & 2 & 8 & $5^{\circ}$ \\
\hline Falta de espaço para produção & 3 & 2 & 1 & 6 & $6^{\circ}$ \\
\hline Ampliação da estrutura física da indústria & 2 & 1 & 2 & 4 & $7^{\circ}$ \\
\hline
\end{tabular}

Fonte: os autores (2020).

Com o desenvolvimento da matriz GUT é possível listar as ações prioritárias, e a partir da mesma foi possível desenvolver um plano de ação para planejar o período do desenvolvimento de cada ação, que será apresentado nas próximas figuras.

Figura 5 - Plano de ação 1

\begin{tabular}{|c|c|c|c|c|c|}
\hline \multicolumn{6}{|c|}{ Plano de ação: Organização do ambiente } \\
\hline What? & Who? & When? & Where? & Why? & How? \\
\hline O que? & Quem? & Quando? & Onde? & Por quê? & Como? \\
\hline $\begin{array}{l}\text { Aplicação da } \\
\text { ferramenta } 5 \mathrm{~S}\end{array}$ & $\begin{array}{c}\text { Proprietário da } \\
\text { indústria }\end{array}$ & $\begin{array}{l}\text { Segundo } \\
\text { semestre } \\
\text { de } 2020\end{array}$ & $\begin{array}{c}\text { No espaço } \\
\text { físico da } \\
\text { indústria }\end{array}$ & $\begin{array}{l}\text { Ganho de tempo na } \\
\text { linha de produção; } \\
\text { Efetividade na } \\
\text { execução das } \\
\text { atividades }\end{array}$ & $\begin{array}{c}\text { Montagem de } \\
\text { painéis para } \\
\text { acondicionamen } \\
\text { to das } \\
\text { ferramentas; } \\
\text { Definição de um } \\
\text { local para } \\
\text { armazenamento } \\
\text { dos } \\
\text { equipamentos } \\
\text { de uso contínuo }\end{array}$ \\
\hline
\end{tabular}


Fonte: os autores (2020).

Referente a oportunidade de melhoria organização do ambiente, destacouse como plano de ação a aplicação da ferramenta 5S, pois, a mesma contempla todos os aspectos que organização necessita no momento e futuramente também. 0 plano de ação está evidenciado na Figura 5.

Figura 6 - Plano de ação 2

\begin{tabular}{|c|c|c|c|c|c|}
\hline \multicolumn{7}{|c|}{ Plano de ação: Es toque de chapas de MDF } \\
\hline What? & Who? & When? & Where? & Why? & How? \\
\hline O que ? & Quem? & Quando? & Onde? & Por quê? & Como? \\
\hline $\begin{array}{c}\text { Acondicionam } \\
\text { ento das } \\
\text { chapas em } \\
\text { local }\end{array}$ & $\begin{array}{c}\text { Proprietário da } \\
\text { Indústria }\end{array}$ & $\begin{array}{c}\text { Segundo } \\
\text { semestre } \\
\text { adequado }\end{array}$ & $\begin{array}{c}\text { No espaço } \\
\text { físico da } \\
\text { de } 2020 .\end{array}$ & $\begin{array}{c}\text { Prevenção de danos } \\
\text { e desperdícios } \\
\text { ocasionados pelo } \\
\text { mau }\end{array}$ & $\begin{array}{c}\text { Alocação da } \\
\text { matéria-prima } \\
\text { em um único } \\
\text { local. }\end{array}$ \\
\hline
\end{tabular}

Fonte: os autores (2020).

Em segundo momento em ordem de importância destacou-se o estoque de chapas de MDF, ou seja, a matéria-prima. Observando que mal acondicionamento das chapas pode causar danos e desperdícios desnecessários, a busca pela alocação em um único local é evidente e importante, como comtempla no plano de ação da Figura 6.

Figura 7 - Plano de ação 3

\begin{tabular}{|c|c|c|c|c|c|}
\hline \multicolumn{7}{|c|}{ Plano de ação: Iluminação } \\
\hline What? & Who? & When? & Where? & Why? & How? \\
\hline O que ? & Quem? & Quando? & Onde? & Por quê? & Como? \\
Melhorar a & $\begin{array}{c}\text { Proprietário e } \\
\text { técnico } \\
\text { iluminação do } \\
\text { ambiente de } \\
\text { trabalho }\end{array}$ & $\begin{array}{c}\text { Segundo } \\
\text { especializado } \\
\text { em eletrônica }\end{array}$ & $\begin{array}{c}\text { No espaço } \\
\text { de 2020. } \\
\text { físico da } \\
\text { indústria }\end{array}$ & $\begin{array}{c}\text { Melhorar a } \\
\text { qualidade do } \\
\text { trabalho; Evitar } \\
\text { retrabalhos; }\end{array}$ & $\begin{array}{c}\text { Aumento dos } \\
\text { pontos de } \\
\text { iluminação, com } \\
\text { a instalação de } \\
\text { fluorescentes de } \\
\text { maior potência. }\end{array}$ \\
\hline
\end{tabular}

Fonte: os autores (2020).

Como terceiro elemento, destaca-se a importância de um plano de ação para melhorias na iluminação da indústria, para assim diminuir e evitar retrabalhos, melhorando consequentemente a qualidade e o ambiente de produção, o plano de ação está contemplado na Figura 7. 
Figura 8 - Plano de ação 4

\begin{tabular}{|c|c|c|c|c|c|}
\hline \multicolumn{6}{|c|}{ Plano de ação: Refugos } \\
\hline What? & Who? & When? & Where? & Why? & How? \\
\hline O que? & Quem? & Quando? & Onde? & Por quê? & Como? \\
\hline $\begin{array}{c}\text { Orientar o } \\
\text { proprietário } \\
\text { quanto as } \\
\text { formas de } \\
\text { descarte. } \\
\text { Reutilização } \\
\text { de refugos em } \\
\text { novos } \\
\text { projetos. }\end{array}$ & $\begin{array}{c}\text { Proprietário da } \\
\text { indústria }\end{array}$ & $\begin{array}{c}\text { Segundo } \\
\text { semestre } \\
\text { de } 2020\end{array}$ & $\begin{array}{l}\text { Na linha de } \\
\text { produção }\end{array}$ & $\begin{array}{l}\text { Redução de custos. } \\
\text { Melhoria no } \\
\text { processo produtivo. } \\
\text { Aumento do espaço } \\
\text { de produção. }\end{array}$ & $\begin{array}{c}\text { Verificação das } \\
\text { peças para } \\
\text { reutilização }\end{array}$ \\
\hline
\end{tabular}

Fonte: os autores (2020).

Outro elemento importante são os refugos produzidos pela produção, dessa maneira buscou-se desenvolver um plano de ação para orientação adequada dos mesmos e, em outros momentos, a reutilização em novos projetos. 0 plano de ação está evidenciado na Figura 8.

Figura 9 - Plano de ação 5

\begin{tabular}{|c|c|c|c|c|c|}
\hline \multicolumn{6}{|c|}{ Plano de ação: Álbum de apres entação de projetos finalizados } \\
\hline What? & Who? & When? & Where? & Why? & How? \\
\hline O que? & Quem? & Quando? & Onde? & Por quê? & Como? \\
\hline \begin{tabular}{|} 
Oportunizar \\
aos clientes \\
acesso a \\
projetos \\
confeccionado \\
s pela \\
indústria \\
anteriormente.
\end{tabular} & $\begin{array}{l}\text { Proprietário da } \\
\text { indústria e } \\
\text { equipe } \\
\text { especializada }\end{array}$ & $\begin{array}{c}\text { Segundo } \\
\text { semestre } \\
\text { de } 2020\end{array}$ & $\begin{array}{c}\text { No espaço } \\
\text { físico da } \\
\text { indústria }\end{array}$ & $\begin{array}{c}\text { Contribuir com o } \\
\text { cliente para sua } \\
\text { tomada de decisão. } \\
\text { Ofertar projetos que } \\
\text { venham a gerar } \\
\text { interesse no cliente. }\end{array}$ & $\begin{array}{l}\text { Sistema com } \\
\text { registro de } \\
\text { projetos } \\
\text { finalizados com } \\
\text { fotos, materiais } \\
\text { utilizados e } \\
\text { layout } \\
\text { diferenciado em } \\
\text { cada ambiente. }\end{array}$ \\
\hline
\end{tabular}

Fonte: os autores (2020).

Durante as visitas e entrevistas realizadas evidenciou-se a inexistência de um catálogo de produtos já fabricados pela indústria moveleira, sendo um fator importante, pois, interfere diretamente na apresentação e tomada de decisão final do cliente no projeto a ser executado. 0 plano de ação está apresentado na Figura 9. 
Figura 10 - Plano de ação 6

\begin{tabular}{|c|c|c|c|c|c|}
\hline \multicolumn{6}{|c|}{ Plano de ação: Es paço restrito } \\
\hline What? & Who? & When? & Where? & Why? & How? \\
\hline O que? & Quem? & Quando? & Onde? & Por quê? & Como? \\
\hline $\begin{array}{l}\text { Estudar uma } \\
\text { alteração do } \\
\text { layout e } \\
\text { possibilidade } \\
\text { do aumento } \\
\text { do mesmo }\end{array}$ & $\begin{array}{l}\text { Proprietário da } \\
\text { indústria e } \\
\text { equipe } \\
\text { especializada }\end{array}$ & $\begin{array}{c}\text { Primeiro } \\
\text { semestre } \\
\text { de } 2021\end{array}$ & $\begin{array}{c}\text { No espaço } \\
\text { físico da } \\
\text { indústria }\end{array}$ & $\begin{array}{l}\text { Atender a demanda } \\
\text { de produção de } \\
\text { forma satisfatória. } \\
\text { Entrega dos } \\
\text { produtos no prazo } \\
\text { estipulado. Melhora } \\
\text { no desempenho do } \\
\text { fluxo de produção. }\end{array}$ & $\begin{array}{c}\text { Reestruturar o } \\
\text { layout atual. } \\
\text { Disponibilização } \\
\text { de espaço } \\
\text { suficiente para } \\
\text { adiantamento de } \\
\text { pedidos } \\
\text { recentes e } \\
\text { executa-los em } \\
\text { horários vagos. }\end{array}$ \\
\hline
\end{tabular}

Fonte: os autores (2020).

Na Figura 10 apresenta-se um plano de ação por conta de a organização possuir um espaço restrito, o que afeta diretamente na capacidade produtiva e na antecipação de pedidos. Elencou-se um plano de ação importante, porque afeta diretamente a organização e precisa ser pensando em ser colocado em execução para os próximos anos.

Figura 11 - Plano de ação 7

\begin{tabular}{|c|c|c|c|c|c|}
\hline \multicolumn{6}{|c|}{ Plano de ação: Ampliação da es trutura física da indus tria } \\
\hline What? & Who? & When? & Where? & Why? & How? \\
\hline O que? & Quem? & Quando? & Onde? & Por quê? & Como? \\
\hline $\begin{array}{c}\text { Aumento do } \\
\text { espaço físico } \\
\text { da industria } \\
\text { para melhorar } \\
\text { a execução } \\
\text { das atividades } \\
\text { e } \\
\text { deslocamento } \\
\text { dos móveis }\end{array}$ & $\begin{array}{c}\text { Proprietário da } \\
\text { indústria e } \\
\text { equipe } \\
\text { especializada }\end{array}$ & $\begin{array}{c}\text { Segundo } \\
\text { semestre } \\
\text { de } 2020\end{array}$ & $\begin{array}{c}\text { No espaço } \\
\text { físico da } \\
\text { indústria }\end{array}$ & $\begin{array}{c}\text { Possibilidade de } \\
\text { executar mais de } \\
\text { um projeto aos } \\
\text { mesmo tempo } \\
\text { disponível. Estoque } \\
\text { intermediário de } \\
\text { móveis acabados } \\
\text { em serviços, } \\
\text { possibilitando o } \\
\text { adiantamento de } \\
\text { prazos de produção. } \\
\text { Maior estoque de } \\
\text { matéria-prima em } \\
\text { períodos } \\
\text { promocionais }\end{array}$ & $\begin{array}{c}\text { Remodelação } \\
\text { do espaço físico } \\
\text { com a criação } \\
\text { de uma sala de } \\
\text { recepção aos } \\
\text { clientes. Divisão } \\
\text { da área de } \\
\text { produção: } \\
\text { estoque, } \\
\text { almoxarifado, } \\
\text { corte, } \\
\text { montagem, } \\
\text { expedição e } \\
\text { área de refugos } \\
\text { de matéria- } \\
\text { prima. }\end{array}$ \\
\hline
\end{tabular}

Fonte: os autores (2020).

E, por fim, na Figura 11 destaca-se o plano de ação para ampliação da estrutura física, que comtempla diferentes aspectos da organização, principalmente na criação de uma sala de espera adequada e a divisão de setores. 
O plano de ação bem estruturado é possível que a organização elimine as não conformidades existentes, com o objetivo de melhorias no negócio e agregação de mais valor nos produtos ofertados. Desse modo, as sugestões devem ser analisadas e colocadas em prática o quanto antes, para assim, agregar resultados e melhorias constantes no processo produtivo.

\section{CONSIDERAÇÕES FINAIS}

As empresas em âmbito geral necessitam desafiar-se em atender as exigências do mercado frente aos concorrentes e consumidores. Assim, necessitam gerenciar os seus meios produtivos para atender essa complexidade, que ocorre por meio da análise dos processos produtivos, compreendendo suas condições atuais e oportunidades de melhorias.

Destaca-se que o presente estudo buscou propor ações de melhorias no processo produtivo da indústria moveleira. Desse modo, para a concretização da pesquisa teve-se a necessidade de realizar a caracterização da empresa, buscando informações sobre seu respectivo histórico, clientes, produtos fabricados e principalmente sobre seu processo e ambiente de produção.

Quanto aos objetivos específicos, todos foram atendidos da realização de visitas e entrevistas, sendo apresentados os diversos produtos produzidos pela indústria, o desenvolvimento do mapeamento do processo produtivo, apresentado através do fluxograma com sua posterior descrição, a identificação de oportunidades de melhorias em todo o ambiente organizacional e, por fim, a identificação de ações de melhorias no processo produtivo, sendo apresentado nos planos de ações de cada atividade.

Assim, destaca-se que a problemática da pesquisa foi respondida por meio da identificação de oportunidades e desenvolvimento do plano de ação para, posteriormente, realizar a execução das mesmas, garantindo maior credibilidade, organização e rendimento nas tarefas executadas.

Desse modo, destaca-se a importância da área da Administração da Produção nas organizações, contribuindo constantemente com as ferramentas da qualidade e gerenciamento das mesmas. Por fim, evidencia-se a relevância da pesquisa e a disponibilidade da continuação da pesquisa na organização, trabalhando outros objetivos organizacionais como a implantação da ferramenta $5 \mathrm{~S}$.

\section{LIMITAÇÕES E SUGESTÕES DE NOVOS ESTUDOS}

Referente a limitações encontradas nota-se a incompatibilidade de horário com o proprietário e equipe de trabalho, por estar sobrecarregado por conta da alta demanda de pedidos; contudo o proprietário contribuiu significativamente com a pesquisa, disponibilizando-se para desenvolvimento de mais projetos. Em relação a estudos futuros sugere-se a aplicação das ações propostas junto à indústria, com o intuito de comparar resultados e mensurar os ganhos obtidos com as ações propostas. 


\section{REFERÊNCIAS}

CAMARGO, Wellington. Controle de Qualidade Total. Ed: Instituto Federal Paraná. 2011.

CORRÊA, H. L.; GIANESI, I. G. N.; CAON, M. Planejamento, programação e controle da produção. 5. ed. - São Paulo: Atlas, 2008.

CHIAVENATO, Idalberto. Introdução à teoria geral da administração. 7. ed. - Rio de Janeiro: Elsevier, 2004.

CHIZZOTTI, A. Pesquisa em ciências humanas e sociais. 8. ed. - São Paulo: Cortez. 2006.

CURY, Antônio. Organização e métodos: uma visão holística. São Paulo: Atlas. 2006.

DAVIS, Mark M.; AQUILANO, Nicholas J.; CHASE, Richard B. Fundamentos da administração da produção. Porto Alegre: Bookman, 2001.

GÜLLICH, Roque Ismael Costa; LOVATO; Adalberto; EVANGELISTA, Mario Luiz Santos. Metodologia da pesquisa: normas para apresentações de trabalhos - redação, formatação e editoração. 2. ed. Três de Maio: SETREM, 2007.

LOVATO, Adalberto. Metodologia da pesquisa. Três de Maio: SETREM. 2013.

MACHADO, Simone Silva. Gestão da qualidade. Instituto Federal de Educação, Ciência e Tecnologia de Goiás/IFG-Inhumas e a Universidade Federalde Santa Maria para o Sistema Escola Técnica Aberta do Brasil - Rede e-Tec Brasil. 2012.

MARCONI, M. A.; LAKATOS, E. M. Técnicas de pesquisa. 8. ed. Ed. São Paulo: Atlas. 2018.

PARANHOS FILHO, Moacyr. Gestão da produção Industrial. Curitiba: IBPEX, 2007.

PRADELLA, S.; FURTADO, J. C.; KIPPER, L. M. Gestão de processos da teoria à prática: aplicando a metodologia de simulação para a otimização do redesenho de processos. São Paulo: Atlas, 2012.

RIVAS JUNIOR, Almir F. Ferramenta 5W2H. 2010. Disponível em: http://pt.scribd.com/doc/25493634/como-fazer-um-plano-de-acao-5W2H-e-um-modelo-deexemplo-em-planilha. Acesso em: 2 abr. 2020.

SCUCUGLIA, Rafael. Como mapear seus processos. [online]. 2007. Disponível em: https://gaussconsulting.com.br/wp-content/uploads/2013/05/artigo_como_mapear_ seus_processos.pdf. Acesso em: 7 maio 2020.

SLACK, Nigel; BRANDON-JONES, Alistair; JOHNSTON, Robert. Administração da produção. Tradução de Daniel Vieira. 8. ed. - São Paulo: Atlas, 2018.

SLACK, N.; CHAMBERS, S.; JOHNSTON, R. Administração da produção. 3. ed, - São Paulo: Atlas, 2009.

VIEIRA FILHO, Geraldo. Gestão da qualidade total: uma abordagem prática. 4. ed. - Campinas, SP: Alínea, 2012. 